\title{
Disruption of NPI Licensing: the Case of Presuppositions
}

\author{
Vincent Homer \\ University of California, Los Angeles
}

\section{Introduction}

The main goal of this paper is to establish empirically that, contrary to the view best represented by von Fintel (1999), the licensing of NPIs can be disrupted by presuppositions. We provide original data in English and Romance, and make the novel observation that weak NPIs are sensitive to some but not all presuppositions, while strong NPIs are sensitive to all of them. Section 1 presents evidence in support of our claim; section 2 argues that presuppositions should be included in the meaning relevant for NPI licensing and draws a parallel with implicatures; section 3 exposes the flaws of Strawson-entailment, which ensures licensing in the presence of presuppositions; in section 4, we offer reasons to prefer our theory of licensing based on strict downward entailingness.

As a preliminary clarification, we state the licensing condition we adopt in the paper:

(1) Licensing Condition (after Gajewski 2005):

An NPI $\alpha$ is licensed in a sentence S only if there is a constituent $\beta$ of S containing $\alpha$ such that $\beta$ is Downward Entailing with respect to the position of $\alpha$.

(2) A constituent $\beta$ is Downward Entailing with respect to the position of $\alpha$ $\left(\llbracket \alpha \rrbracket \in \mathrm{D}_{\sigma}\right)$ iff the function $\lambda x . \llbracket \beta\left[\alpha / v_{\sigma}\right] \rrbracket^{g\left[v_{\sigma} \rightarrow x\right]}$ is Downward Entailing (a function $F$ is DE iff for all A, B in the domain of $F$ such that $\mathrm{A} \Rightarrow \mathrm{B}, F(\mathrm{~B})$ $\Rightarrow F(\mathrm{~A})$, where ' $\Rightarrow$ ' stands for cross-categorial entailment).

\section{Evidence}

We produce data which evidence the disrupting effect of some presupposition triggers on licensing: the first subsection deals with weak NPIs, i.e. any, ever, care to, bother with, and the second subsection covers strong NPIs such as in years/ months/weeks, until, either, all that or the minimizers lift a finger, budge an inch, sleep a wink.

Thanks to Philippe Schlenker, to Natasha Abner, Daniel Büring, Gennaro Chierchia, Michelangelo Falco, Kai von Fintel, Danny Fox, Asia Furmanska, Jon Gajewski, Benjamin George, Irene Heim, Nicolas Lacasse, Robyn Orfitelli, Nathaniel Porter, Matteo Residori, J'aime Roemer, Craig Sailor, Molly Shilman, Benjamin Spector, Dominique Sportiche, Chad Vicenik, and to the audiences at the seminar on presupposition taught by Philippe Schlenker at UCLA in the fall of 2007, and at the Syntax-Semantics Seminar at UCLA. This work was supported in part by NSF grant BCS-0617316. 


\subsection{Weak NPIs}

To our knowledge, the disruptive potential of too has never been noticed.

(3) Context: Mary read some interesting book. ${ }^{1}$

a. *I don't think $[\mathrm{John}]_{F}$ read anything interesting too.

b. I don't think $[\mathrm{John}]_{F}$ read something interesting too.

c. Presupposition of ( $3 b)$ : Somebody other than John read something interesting.

Crucially, the ungrammaticality of (3a) is not due to some incompatibility between too and the negation, as shown by the well-formedness of (3b).

The singular definite article and both are disruptors as well (this observation is not new, unlike the one about too, see Lahiri 1998, Giannakidou 2006, Guerzoni and Sharvit 2007 inter alia):

(4) Context: There is exactly one student who read some books on NPIs.

a. ${ }^{*}$ The student who read any books on NPIs is selling them.

b. The student who read books on NPIs is selling them.

c. Presupposition of (4b): There is exactly one student who read books on NPIs.

(5) Context: Exactly two students read some linguistics books.

a. *Both students who read any linguistics books have applied to the department.

b. Both students who read linguistics books have applied to the department.

c. Presupposition of $(5 b)$ : There are exactly two students who read linguistics books.

The equivalents of too, singular the and both are disruptors in French and Italian as well. These two languages feature several other disruptors, beyond the ones just mentioned: for example an NPI in the complement clause of a French cognitive factive predicate like savoir 'know', réaliser 'realize', se rendre compte 'become aware', etc. and their Italian equivalents is not licensed (but a weak NPI would be in English), despite the presence of a superordinate negation (i.e. a DE function):

(6) Context: Marie is the best player in the tournament.

a. *Jean ne sait pas que Marie a la moindre chance de Jean NEG knows NEG that Marie have.IND the slightest chance of gagner (French) win

'Jean doesn't know that Marie has any chance to win.'

\footnotetext{
${ }^{1}$ In this example and in the rest of the paper, we supply contexts in order to avoid unacceptability due to a presupposition failure. We also spell out presuppositions; for ungrammatical sentences, we provide a grammatical paraphrase and its presupposition.
} 
b. Jean ne sait pas que Marie a une ('some') chance de gagner.

c. Presupposition of $(6 b)$ : Marie has some chance to win.

When the verb penser 'think', which is not a presupposition trigger, is substituted for the verb savoir 'know', the disruption effect vanishes:

a. Jean ne pense pas que Marie a/ait la moindre chance Jean NEG thinks $\overline{N E G}$ that Marie have.IND/SUBJ the slightest chance de gagner (French) of win

'Jean doesn't think that Marie has any chance to win.'

b. Presupposition: None.

In Italian, an epistemic predicate, when negated, tends to require the subjunctive mood in the embedded clause; the indicative is also possible though, but in this configuration, it triggers the presupposition that the speaker holds true the complement clause (Homer 2007). The following pair shows that the indicative, unlike the subjunctive, disrupts the licensing of the NPI mai 'ever':

(8) Context: Maria has visited Paris several times.

a. *Gianni non pensa che Maria $\grave{e}$ mai andata a Parigi Gianni NEG thinks that Maria be.IND ever gone to Paris (Italian) 'Gianni doesn't think that Maria has ever been to Paris.'

b. Gianni non pensa che Maria è andata a Parigi.

c. Presupposition of $(8 b)$ : The speaker believes that Maria has been to Paris.
a. Gianni non pensa che Maria sia mai andata a Parigi
Gianni NEG thinks that Maria be.SUBJ ever gone to Paris
'Gianni doesn't think that Maria has ever been to Paris.'
b. Presupposition: None.

In the same connection, a cognitive factive verb like se souvenir 'remember' in French allows the indicative/subjunctive alternation when negated. The indicative yields the presupposition that the complement clause is true, and acts as a disruptor, while the subjunctive doesn't:

(10) Context: Marie warned Jean against drinking alcohol.

a. *Jean ne se souvient pas que Marie lui $a$ dit Jean NEG REFL remembers NEG that Marie to-him have.IND said quoi que ce soit (French) anything 'Jean doesn't remember that Marie told him anything.'

b. Jean ne se souvient pas que Marie lui a dit quelque chose ('something').

c. Presupposition of (10b): Marie said something to Jean. 
a. Jean ne se souvient pas que Marie lui ait dit Jean NEG REFL remembers NEG that Marie to-him have.SUBJ said quoi que ce soit (French) anything 'Jean doesn't remember that Marie told him anything.'

b. Presupposition: None.

In both French and Italian, the effect of presupposition is also felt with the counterparts of the triggers why and how (while NPIs are normally licensed in questions).

(12) Context: Marie wrote three letters to her mother.

a. *Pourquoi/Comment Marie a-t- elle écrit quoi que ce soit à sa Why/How Marie has she written anything to her mère? (French) mother?

'Why/How has Marie written anything to her mother?'

b. Pourquoi/Comment Marie a-t-elle écrit à sa mère ?

c. Presupposition of (12b): Marie wrote something to her mother.

Interestingly, why and how do not always trigger a presupposition: they do when the clausemate verb is in the indicative mood (as in 12a), but they don't when it is in the infinitive or in the conditional mood (as in 13a below). The disruption effect correlates exactly with the presence of a presupposition:

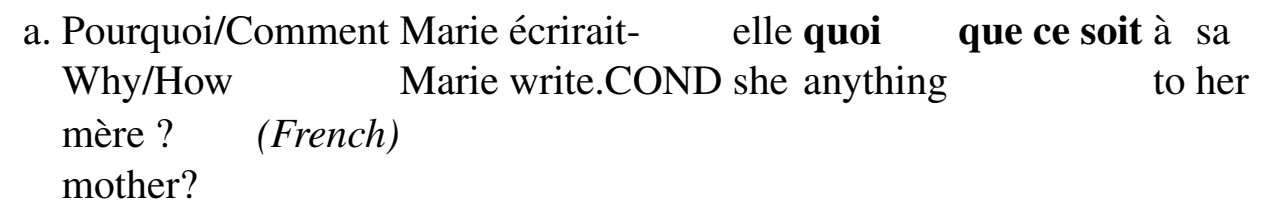

a. Pourquoi/Comment Marie écrirait- elle quoi que ce soit à sa Why/How Marie write.COND she anything to her mère? (French) mother?

'Why/How would Marie write anything to her mother?'

b. Presupposition: None.

\subsection{Strong NPIs}

There is a remarkable difference between weak and strong NPIs: the licensing of the former (as we've just seen) is vulnerable to some but not all presupposition triggers, whereas the licensing of the latter is consistently disrupted by all presupposition triggers. This is true in English, French and Italian.

(14) Context: John got Mary an apartment, although they were not friends.

a. *Why did John lift a finger to help Mary?

b. Why did John help Mary?

c. Presupposition of (14b): John helped Mary.

(15) Context: Mary must have been helped, she can't have lifted the piano alone. 
a. *I doubt that it was John who lifted a finger to help Mary.

b. I doubt that it was John who helped Mary.

c. Presupposition of (15b): Someone helped Mary.

(16) Context: John slept a solid 10 hours last night.

a. *Mary doesn't know that John slept a wink.

b. Mary doesn't know that John slept.

c. Presupposition of (16b): John slept.

(17) Context: John visited Mary three times over the past 10 years.

a. *Only John has visited Mary in years.

b. Only John has visited Mary.

c. Presupposition of (17b): John has visited Mary.

(18) Context: Betty was told that her husband visited Mary three times over the past 10 years.

a. *Betty is sorry that her husband has visited Mary in years.

b. Betty is sorry that her husband has visited Mary.

c. Presupposition of (18b): Betty thinks that her husband has visited Mary.

(19) Context: Bill was told that Mary exercised last week.

a. *Bill is surprised that Mary has exercised in years.

b. Bill is surprised that Mary has exercised.

c. Presupposition of (19b): Bill thinks that Mary has exercised.

\section{Analysis}

In the previous section, we observed that presupposition triggers are potential disruptors. Is it to say that the mere presence of a presupposition trigger in the constituent upon which licensing is checked can suffice to cause a disruption? To answer this question, let's turn to the very significant minimal pair formed by (3a) (repeated as 20a below) and (21a), in which either replaces too:

(20) Context: Mary read some interesting book.

a. *I don't think $[\mathrm{John}]_{F}$ read anything interesting too.

b. Presupposition of $(3 b)$ : Somebody other than John read something interesting.

(21) Context: Mary didn't read anything interesting.

a. I don't think [John $]_{F}$ read anything interesting either. 
b. Presupposition: Somebody other than John didn't read anything interesting.

Given that too and either are very close in meaning but differ with respect to their presuppositions, it is reasonable to think that it is this difference which explains the contrast between (20a) and (21a): contrary to sentence (21b), sentence (20b), which expresses the presupposition of the closest grammatical paraphrase of (20a), contains no subconstituent that is downward entailing with respect to the position of the object of the verb read (the same position that anything occupies in 20a). This discrepancy can only matter to the occurrence of anything in (20a) and (21a) if the process of checking the licensing of the NPI involves considering an enriched meaning which includes, for each sentence, the presuppositions it carries.

We thus assume that, alongside the plain meaning of a given sentence $\Phi$, grammar provides an enriched meaning of $\Phi$ (henceforth labeled the $\mu$ meaning of $\Phi$ and noted $\mu(\llbracket \Phi \rrbracket)$ ), which is the conjunction of the assertive content of $\Phi$ and of (the conjunction of) its presuppositions; ${ }^{2}$ it is the $\mu$ meaning that counts for NPI licensing. one: ${ }^{3}$

The effect of the $\mu$ operator is to turn a trivalent meaning into a bivalent

Let $\mathrm{E}$ be a trivalent meaning. $\mu(\mathrm{E})=0$ iff $\mathrm{E}=\#$ or 0 and $\mu(\mathrm{E})=1$ iff $\mathrm{E}=1$

In order to show that the ungrammatical (20a) (repeated as 23a below) doesn't provide a downward entailing environment for the NPI anything, we check in (23b)(23c) whether some constituent of type $<t>$ of the sentence supports an inference from sets to subsets in the relevant position (the set of novels is a subset of the set of books). The constituent we examine is the whole sentence, for the embedded clause lacks any expression denoting a DE function (and as such cannot be a DE constituent). Importantly, we compute an inference from a $\mu$ meaning to another $\mu$ meaning:

a. *I don't think $[\mathrm{John}]_{F}$ read anything interesting too.

b. I don't think [John $]_{F}$ read a book too.

Presupposition: Somebody other than John read a book.

c. I don't think $[\mathrm{John}]_{F}$ read a novel too.

Presupposition: Somebody other than John read a novel.

$$
\begin{aligned}
& \mu(\llbracket(23 \mathrm{~b}) \rrbracket)=\neg[\llbracket \text { a book } \rrbracket[\lambda y . \operatorname{read}(j, y)]] \wedge \exists x[x \neq j \wedge \llbracket \text { a book } \rrbracket[\lambda y \cdot \operatorname{read}(x, y)]] \\
& \mu(\llbracket(23 \mathrm{c}) \rrbracket)=\neg[\llbracket \text { a novel } \rrbracket[\lambda y . \operatorname{read}(j, y)]] \wedge \exists x[x \neq j \wedge \llbracket \text { a novel } \rrbracket[\lambda y . \\
& \operatorname{read}(x, y)]]
\end{aligned}
$$

\footnotetext{
${ }^{2}$ Given the definition of the $\mu$ operator, we are led to stipulate that the licensing condition should require that the constituent upon which licensing is checked be of type $\langle t\rangle$. We thus propose the following formulation: An NPI $\alpha$ is licensed in a sentence $\mathrm{S}$ only if there is a constituent $\beta$ of type $<t>$ of $\mathrm{S}$ containing $\alpha$ such that the function $\lambda x . \mu\left(\llbracket \beta\left[\alpha / v_{\sigma}\right] \rrbracket^{g\left[v_{\sigma} \rightarrow x\right]}\right)$ is Downward Entailing.

${ }^{3}$ As an alternative to building conjunctions, we could adopt the rule that in a trivalent framework, $F$ entails $G$ iff whenever $\llbracket F \rrbracket=1, \llbracket G \rrbracket=1$. Thanks to B. Spector for suggesting this solution; we will use conjunctions ( $\mu$ meanings) as a pedagogical device.
} 


$$
\mu(\llbracket(23 b) \rrbracket) \not \Rightarrow \mu(\llbracket(23 c) \rrbracket)
$$

The $\mu$ meaning of (23b) fails to entail the $\mu$ meaning of (23c), leading to ungrammaticality. We now apply the same procedure to the grammatical (21a), repeated as (26a) below:

(26) a. I don't think [John $]_{F}$ read anything interesting either.

b. I don't think [John $]_{F}$ read a book either.

Presupposition: Somebody other than John didn't read a book.

c. I don't think [John $]_{F}$ read a novel either.

Presupposition: Somebody other than John didn't read a novel.

$\mu(\llbracket(26 \mathrm{~b}) \rrbracket)=\neg[\llbracket$ a book $\rrbracket[\lambda y . \operatorname{read}(j, y)]] \wedge \exists x[x \neq j \wedge \neg \llbracket$ a book $\rrbracket[\lambda y$. $\operatorname{read}(x, y)]]$

$\mu(\llbracket(26 \mathrm{c}) \rrbracket)=\neg[\llbracket$ a novel $\rrbracket[\lambda y . \operatorname{read}(j, y)]] \wedge \exists x[x \neq j \wedge \neg \llbracket$ a novel $\rrbracket[\lambda y$. $\operatorname{read}(x, y)]]$

$$
\mu(\llbracket(26 \mathrm{~b}) \rrbracket) \Rightarrow \mu(\llbracket(26 \mathrm{c}) \rrbracket)
$$

Our claim that the makeup of the presuppositions is a crucial matter for NPI licensing yields an interesting prediction: it should be possible to construct a grammatical sentence whose LF exhibits the same scopal relationships between negation, too and the NPI as the ill-formed (23a) (namely NOT $>$ TOO $>$ ANY), but whose presupposition is DE with respect to the relevant position. The position the NPI occupies in the sentence would thus be DE in the assertive content as well as in the presupposition, leading to grammaticality. ${ }^{4}$

Such a sentence exists, witness (29a) below:

(29) Context: Many students in Mary's class read a very interesting book.

a. I don't think [anybody in John's class] $F$ read something interesting too.

b. Presupposition: Somebody other than anybody in John's class read something interesting.

(30) a. I don't think [a student $]_{F}$ read something interesting too.

Presupposition: Somebody other than a student read something interesting.

b. I don't think [a French student $]_{F}$ read something interesting too.

Presupposition: Somebody other than a French student read something interesting.

(31) $\quad \mu(\llbracket(30 \mathrm{a}) \rrbracket)=\neg \exists x[x \in \llbracket$ student $\rrbracket \wedge \llbracket$ something interesting $\rrbracket[\lambda y \cdot \operatorname{read}(x, y)]] \wedge$ $\exists x[x \notin \llbracket$ student $\rrbracket \wedge \llbracket$ something interesting $\rrbracket[\lambda y \cdot \operatorname{read}(x, y)]]$

\footnotetext{
${ }^{4}$ Let $F$ and $G$ be DE functions. For all A, B such that B $\Rightarrow \mathrm{A}, F(\mathrm{~A}) \wedge G(\mathrm{~A}) \Rightarrow F(\mathrm{~B}) \wedge G(\mathrm{~B})$.
} 
$\mu(\llbracket(30 \mathrm{~b}) \rrbracket)=\neg \exists x[x \in \llbracket$ French student $\rrbracket \wedge \llbracket$ something interesting $\rrbracket[\lambda y \cdot \operatorname{read}(x, y)]]$ $\wedge \exists x[x \notin \llbracket$ French student $\rrbracket \wedge \llbracket$ something interesting $\rrbracket[\lambda y \cdot \operatorname{read}(x, y)]]$

$$
\mu(\llbracket(30 \mathrm{a}) \rrbracket) \Rightarrow \mu(\llbracket(30 \mathrm{~b}) \rrbracket)
$$

The contrast between (23a) and (29a) shows that we rightly invoke the presupposition triggered by too as the cause of the ill-formedness of the former.

\section{1. $\mu$ Meanings and Chierchia's Strengthened Meanings}

Our proposal, which points at presuppositions as sources of disruption, is interestingly parallel to the one that Chierchia (2004) makes. Chierchia accounts for the intervention effects caused by and, every, numerals, because-clauses, always, etc. by invoking the role of another kind of inference, namely an indirect scalar implicature.

(33) a. I doubt that every housemate of Sue has potatoes.

b. *I doubt that every housemate of Sue has any potatoes.

c. *LF: Doubt ... every ... NPI.

Chierchia's intuition is that and, every, numerals, etc. form a natural class: they are all strong scalar items (e.g. <every, most, some $>,<$ and, or $>$ ). When placed under a DE operator, they yield an indirect scalar implicature. Grammar provides two meanings for a given sentence $\Phi$, namely the plain meaning, i.e the truth conditions of $\Phi$, and the strong one, noted $\llbracket \Phi \rrbracket^{s}$, i.e. the conjunction of the truth conditions and implicatures of $\Phi$. It is the latter meaning which is relevant for NPI licensing. ${ }^{5}$

*It is not the case that everybody has any roses.

a. It is not the case that everybody has roses. Scalar Implicature: Somebody has roses.

b. It is not the case that everybody has blue roses. Scalar Implicature: Somebody has blue roses.

$\llbracket(35 \mathrm{a}) \rrbracket^{s}=\neg[\forall x(\llbracket$ roses $\rrbracket(\lambda y \cdot x$ have $y))] \wedge \exists x(\llbracket$ roses $\rrbracket(\lambda y . x$ have $y))$

$\llbracket(35 \mathrm{~b}) \rrbracket^{s}=\neg[\forall x(\llbracket$ blue roses $\rrbracket(\lambda y . x$ have $y))] \wedge \exists x(\llbracket$ blue roses $\rrbracket(\lambda y . x$ have y))

$$
\llbracket(35 \mathrm{a}) \rrbracket^{s} \nRightarrow \llbracket(35 \mathrm{~b}) \rrbracket^{s}
$$

The discovery that presuppositions can disrupt licensing brings to light interesting commonalities between the two types of inferences.

\footnotetext{
${ }^{5}$ This presentation of Chierchia (2004) is a blatant oversimplification: in particular, we are pretending that this proposal features a licensing condition in terms of DEness, which is not in fact the case: the condition invokes the widening of the domain of quantification brought about by the NPI, and this widening is only licit if it leads to strenghtening.
} 


\subsection{Interesting Consequences}

The present paper offers the first touchstone that can differentiate local accommodation and non-projection on the one hand, and non-triggering on the other.

\subsubsection{Local Accommodation and Non-Projection}

The disruption effect remains even when the presupposition is locally accommodated (i.e. made part of the assertive content in the scope of negation), as in (39):

(38) The King of France is not bald, because there is no King of France.

(39) *Pierre ne $s$ ' aperçoit pas que Marie a la moindre chance, Pierre NEG REFL perceives NEG that Marie has the slightest chance, car elle n' a aucune chance (French) for she NEG has no chance

'Pierre doesn't realize that Marie has any chance, for she has no chance.'

Similarly, the effect remains if the presupposition is satisfied, as in (40) (the presupposition of the consequent is satisfied by the antecedent):

(40) *I doubt that if Peter went to Paris, $[\text { Mary }]_{F}$ too ever went to Paris.

Once triggered, presuppositions cause a disruption, as if the system responsible for NPI licensing processed them blindly. Strikingly, the intervention effects studied by Chierchia also persist when the inference (a scalar implicature) is defeated:

(41) *The students have no background whatsoever, so I doubt that every student has any background.

\subsubsection{Non-Triggering}

The disruption effect does not obtain when the presupposition is simply not triggered. This can be illustrated with a French cognitive factive predicate like s'apercevoir 'realize', which doesn't yield a presupposition when placed in the antecedent of a subjunctive conditional:

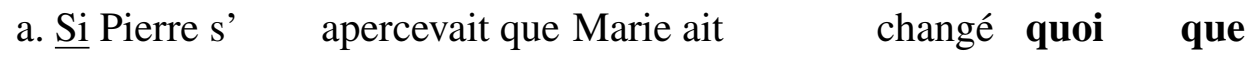
If Pierre REFL perceived that Marie have.SUBJ changed anything ce soit, il serait en colère , he would-be in wrath

'If Pierre found out that Marie changed anything, he would be mad.'

b. Presupposition: None.

A similar phenomenon occurs with implicatures. A numeral like 11 is not always high on its scale, and it can actually be the weakest element of a truncated scale (e.g. in a context where one groups numerals by multiples of 11): then no indirect scalar implicature is triggered, hence the grammaticality of (43a): 
a. (A soccer coach can say...) I never had eleven kids who won any championship. (Chierchia 2004)

b. *I didn't meet eleven people who read any of my poetry. (Ch. 2004)

\section{Strawson-Entailment}

Our novel observations and the consequent claim about the disruption caused by presuppositions run counter to the commonly accepted view that such an effect simply does not exist. It must be said that a number of presupposition triggers, not only do not disrupt licensing, but seem to cause it. This is notoriously true of sorry, surprise and only.

(44) John is sorry that Mary bought any car.

(45) Meredith is surprised that John has any complaints about the hotel.

(46) Only John ever went to Chicago.

Consider for example (44). Leaving aside for the moment the innovation introduced in the previous section, i.e. $\mu$ meanings, it doesn't seem that the inference between (47a) and (47b) goes through, since one can easily imagine scenarios in which John is sorry that Mary bought a car, and the only car she bought is a Mazda (in which case $47 \mathrm{~b}$ is undefined):

a. John is sorry that Mary bought a car.

Presupposition: John believes that Mary bought a car.

b. John is sorry that Mary bought a Honda.

Presupposition: John believes that Mary bought a Honda.

$$
(47 \mathrm{a}) \Rightarrow ?(47 \mathrm{~b})
$$

But the inference will be truth-preserving if it is part of contextual knowledge that Mary bought a Honda. ${ }^{6}$ Under this assumption, whenever (47a) is true, (47b) is also true, since the assertive content of the former entails the assertive content of the latter, and the latter is, by hypothesis, defined.

This is the intuition underlying the widely acknowledged theory of NPI licensing defended in von Fintel (1999): according to von Fintel, the licensing condition should be weakened, since NPIs are licensed despite the presence of the presupposition triggered by only and the emotive factives surprise and sorry. The weakening consists in granting all presuppositions of the consequence when the validity of a downward inference is assessed. This is the spirit of so-called Strawsonentailment, upon which this theory rests. Hence the following definition of Strawson Downward Entailingness:

\footnotetext{
${ }^{6}$ For legitimate qualms about this claim (after all, it is conceivable, assuming that Mary bought a Honda, that John is sorry that she bought a car but relatively satisfied that she chose this particular brand), see von Fintel (1999).
} 
Strawson Downward Entailingness:

A function $f$ of type $\langle\sigma, t>$ is Strawson Downward Entailing (SDE) iff for all $x, y$ of type $\sigma$ such that $x \Rightarrow y$ and $f(x)$ is defined: $f(y) \Rightarrow f(x)$

The licensing condition (weaker than the one we gave in section 1) argued for in the paper is thus:

(49) von Fintel's (1999) Licensing Condition (to be revised):

An NPI is only grammatical if it is in the scope of an $\alpha$ that is SDE.

This theory aims at characterizing licensers, that is to say, expressions in the scope of which NPIs can occur. It bears saying that it only targets the licensing of English weak NPIs (and is therefore silent about languages other than English and about strong NPIs).

Its two main tenets are:

1. NPIs are licensed by operators (as opposed to environments). This is what one might call the syntactic component of the theory;

2. A necessary condition for being a suitable licenser is Strawson Downward Entailingness. This is the semantic component of the theory.

This theory departs from ours with regard to its two main tenets: our theory invokes the strict downward entailingness of environments. To be sure, von Fintel's theory appears to fare better than ours as far as only and emotive factives (sorry, surprise) are concerned (but see section 4 for discussion):

(50) a. John is sorry that Mary bought a car.

Presupposition: John believes that Mary bought a car.

b. John is sorry that Mary bought a Honda.

Presupposition: John believes that Mary bought a Honda.

$\mu(\llbracket(50 \mathrm{a}) \rrbracket)=\llbracket$ be-sorry $\rrbracket[\wedge \llbracket$ a car $\rrbracket(\lambda y . m$ buy $y)](j) \wedge \llbracket$ believe $\rrbracket\left[{ }^{\wedge} \llbracket\right.$ a car $\rrbracket(\lambda y . m$ buy $y)](j)^{7}$

(52) $\quad \mu(\llbracket(50 \mathrm{~b}) \rrbracket)=\llbracket$ be-sorry $\rrbracket[\wedge \llbracket$ a Honda $\rrbracket(\lambda y . m$ buy $y)](j) \wedge \llbracket$ believe $\rrbracket[\wedge \llbracket$ a Honda $\rrbracket(\lambda y . m$ buy $y)](j)$

$$
\begin{gathered}
\mu(\llbracket(50 \mathrm{a}) \rrbracket) \nRightarrow \mu(\llbracket(50 \mathrm{~b}) \rrbracket) \\
(50 \mathrm{a}) \Rightarrow \text { Strawson }_{(50 \mathrm{~b})}(\text { SDE })
\end{gathered}
$$

\footnotetext{
${ }^{7}$ In this formula, 【 be-sorry $\rrbracket$ is the assertive content of the bracketed predicate (no new presupposition is introduced).
} 


\subsection{Singular the and both}

The theory, in its original formulation, wrongly predicts that an NPI should be licensed in the scope of the singular definite article:

(53) (Context: There is exactly one student who read some books on NPIs.)

* The student who read any books on NPIs is selling them.

(54) a. The student who read a book is selling it.

Presupposition: There is exactly one student who read a book.

b. The student who read a novel is selling it.

Presupposition: There is exactly one student who read a novel.

$$
(54 \mathrm{a}) \Rightarrow^{\text {Strawson }}(54 \mathrm{~b}) \quad(S D E)
$$

Owing to the existence and uniqueness presuppositions carried by singular definite descriptions, in any given model the student who read a book and the student who read a novel are one and the same person: so whatever is predicated of one can also be predicated of the other. This ensures the validity of inferences from sets to subsets but also from subsets to sets. This description of the problem also contains a remedy to it, first identified by Lahiri (1998): one should exclude from the list of suitable licensers the singular definite article, both, and in general, those functions which are Strawson Downward Entailing and Strawson Upward Entailing at the same time:

Strawson Upward Entailingness:

A function $f$ of type $\langle\sigma, t\rangle$ is Strawson Upward Entailing (SUE) iff for all $x, y$ of type $\sigma$ such that $x \Rightarrow y$ and $f(y)$ is defined: $f(x) \Rightarrow f(y)$

In light of these new facts, we amend von Fintel's licensing condition in the following way:

\section{von Fintel/Lahiri's (vFL) Licensing Condition:}

An NPI is only grammatical if it is in the scope of an $\alpha$ that is SDE, non SUE.

The class of suitable licensers (SDE, non SUE) is a proper superset of the class of DE operators. The new licensing condition enables the theory to capture the ungrammaticality of NPIs in the restrictor of singular the and also in the restrictor of both:

(57) (Context: Exactly two students read some linguistics books.)

* Both students who read any linguistics books have applied to the department.

(58) a. Both students who read books have applied to the department. Presupposition: There is a set of exactly two students who read books.

b. Both students who read novels have applied to the department. Presupposition: There is a set of exactly two students who read novels. 


$$
\begin{aligned}
& (58 \mathrm{a}) \Rightarrow{ }^{\text {Strawson }}(58 \mathrm{~b}) \quad(S D E) \\
& (58 \mathrm{~b}) \Rightarrow \text { Strawson }(58 \mathrm{a}) \quad(\text { SUE) }
\end{aligned}
$$

Notice that singular the and both are not problematic for the $\mu$ theory:

$$
\begin{aligned}
& \mu(\llbracket(54 a) \rrbracket) \neq \mu(\llbracket(54 b) \rrbracket) \\
& \mu(\llbracket(58 a) \rrbracket) \neq \mu(\llbracket(58 b) \rrbracket)
\end{aligned}
$$

Despite the fix, the vFL account can be shown to be flawed, as it is too weak to explain the disruption caused by some presupposition triggers scoping above an NPI and below an SDE, non SUE operator. These are what one might want to call intervention effects (more shortcomings are presented in Homer 2008).

\subsection{Intervention}

Supporters of the vFL account should worry about the prediction it makes regarding the scopal configuration NOT $>\mathrm{THE}_{S G}>\mathrm{NPI}$ (by $\mathrm{THE}_{S G}$, we mean the singular definite article). The necessary condition that the NPI should be in the scope of some SDE, non SUE operator is met, because negation is one such operator (although the singular definite article, sandwiched between not and the NPI, is not). However, the fact is that the NPI anything is not licensed in the following sentence, as is correctly predicted by the $\mu$ theory: ${ }^{8}$

(59) (Context: Two men are flirting with Mary; one of the two keeps giving her presents, while the other never offered her anything.)

*I don't think the man who gave Mary anything is very smart.

So the syntactic component of the account (operator-based licensing) appears to be incorrect. But the vFL account could still be right, provided it acknowledged that licensing is checked on environments, for the NPI anything in (59) occurs in an SDE, SUE environment ('I don't think the man who gave Mary a Honda is very smart' Strawson-entails 'I don't think the man who gave Mary a car is very smart', because the definite descriptions in the two sentences refer to the same individual).

Alas, the disruption caused by too in (3a) (repeated as 60a below) poses a critical problem to the von Fintel/Lahiri theory.

(60) Context: Mary read some interesting book.

\footnotetext{
${ }^{8}$ It would be impossible to rephrase the vFL licensing condition by making the negative stipulation that an NPI must not be in the scope of an SDE, SUE operator, given the grammaticality of the scopal configuration $\mathrm{THE}_{S G}>$ NOT $>$ NPI:
}

(1) Context: There is some student who knew nothing about linguistics.

a. The student who didn't know any linguistics passed all his syntax exams.

b. Presupposition: There is some student who knew nothing about linguistics. 
a. *I don't think $[\mathrm{John}]_{F}$ read anything interesting too.

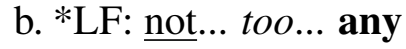

This example invalidates both the syntactic and the semantic components of the theory: it shows that the material intermediate between negation (i.e. a bona fide SDE, non SUE operator) and the NPI can have a disruptive effect on licensing, and the effect is due to the presuppositional nature of this intermediate material. Thanks to the grammatical (29a) repeated as (61a) below (thanks also to the facts about either, see 21a), we know that it is not the mere presence of too in this scopal configuration which precludes the occurrence of the NPI, but, rather, the monotonicity of the presupposition it triggers:

(61) Context: Many students in Mary's class read a very interesting book.

a. I don't think [anybody in John's class] $]_{F}$ read something interesting too.

b. Presupposition: Somebody other than anybody in John's class read something interesting.

Therefore the intervention effect in (60a) consists in a break in the monotonicity of the environment (against the syntactic component), which is crucially not $D E$ (downward inferences from 62a to $62 \mathrm{~b}$ are not licensed on $\mu$ meanings), although it is SDE, non SUE (against the semantic component).

(62) a. I don't think [John $]_{F}$ read a book too.

Presupposition: Somebody other than John read a book.

b. I don't think [John $]_{F}$ read a novel too.

Presupposition: Somebody other than John read a novel.

$$
\begin{gathered}
\mu(\llbracket(62 \mathrm{a}) \rrbracket) \nRightarrow \mu \mu(\llbracket(62 \mathrm{~b}) \rrbracket) \\
(62 \mathrm{a}) \Rightarrow \text { Strawson }(62 \mathrm{~b}) \\
(62 \mathrm{~b}) \nRightarrow \text { Strawson }^{\text {St } 62 \mathrm{a})} \quad(\text { non } S U E)
\end{gathered}
$$

\section{Discussion}

Taking stock, the vFL account is too weak and the $\mu$ theory is too strong. Should the competition end in a tie?

\subsection{Hierarchy}

Let's first take a better view of the data in English and in French. In Tables 1 and 2, a star indicates that the trigger is a disruptor, and a check mark indicates that it isn't.

To this date, we haven't been able to determine the criteria that would predict whether a given trigger is a disruptor or not. But the tables are telling nonetheless. English is strictly more permissive than French: the set of French disruptors is 


\begin{tabular}{|c||c|c|c|c|c|c|}
\hline NPIs: & Why/How & $\begin{array}{c}\text { Cognitive } \\
\text { factives }\end{array}$ & $\begin{array}{c}\text { Sing. definite } \\
\text { article }\end{array}$ & Both & Too & Regret \\
\hline Weak: & $\checkmark$ (rhetorical) & $\checkmark$ & $*$ & $*$ & $*$ & $\checkmark$ \\
\hline Strong: & $*$ & $*$ & $*$ & $*$ & $*$ & $*$ \\
\hline
\end{tabular}

\begin{tabular}{|c||c|c|c|c|c|c|c|}
\hline NPIs: & Surprise & Only & It-Cleft & Again & Before & Stop & Start \\
\hline Weak: & $\checkmark$ & $\checkmark$ & $\checkmark$ & $\checkmark$ & $\checkmark$ & $\checkmark$ & $\checkmark$ \\
\hline Strong: & $*$ & $*$ & $*$ & $? ?$ & $*$ & $*$ & $\checkmark$ \\
\hline
\end{tabular}

Table 1: NPI Licensing in the Scope of Presuppositional Triggers in English

\begin{tabular}{|c||c|c|c|c|c|c|}
\hline NPIs: & Why/How & $\begin{array}{c}\text { Cognitive } \\
\text { factives }\end{array}$ & $\begin{array}{c}\text { Sing. definite } \\
\text { article }\end{array}$ & Both & Too & Regret \\
\hline Weak: & $*$ & $*$ & $*$ & $*$ & $*$ & $\checkmark / ?$ \\
\hline Strong: & $*$ & $*$ & $*$ & $*$ & $*$ & $*$ \\
\hline
\end{tabular}

\begin{tabular}{|c||c|c|c|c|c|c|c|}
\hline NPIs: & Surprise & Only & It-Cleft & Again & Before & Stop & Start \\
\hline Weak: & $\checkmark$ & $\checkmark$ & $\checkmark$ & $\checkmark$ & $\checkmark$ & $\checkmark$ & $\checkmark$ \\
\hline Strong: & $*$ & $*$ & $*$ & $? ?$ & $*$ & $*$ & $\checkmark$ \\
\hline
\end{tabular}

Table 2: NPI Licensing in the Scope of Presuppositional Triggers in French

a proper superset of the set of English disruptors. In turn, the set of Italian disruptors (not displayed here) is a proper superset of the set of French disruptors (e.g. dispiacere 'regret' is a clear disruptor). This suggests an implicational hierarchy among triggers, and the cross-linguistic differences instruct us where to put the breaks (the hierarchy is only partial at this point):

stop, before, it-cleft, only, surprise $>$ regret $>$ cognitive factives $>$ too, singular the, both

If a trigger on the scale is a disruptor in language $L$, any trigger lower on the scale will also be a disruptor in $L$, but the converse is not true $(\alpha>\beta$ reads: ' $\alpha$ is higher on the scale than $\beta$ '). Another important lesson to draw from the tables above is that all strong NPIs in the languages we've considered fall prey to the disruption effect of presuppositions, while only some weak NPIs do. ${ }^{9}$

\footnotetext{
${ }^{9}$ The presupposition of start is DE w.r.t. the relevant position, so its innocuousness, both for weak NPIs and for strong ones, comes as no surprise:

(1) Context: John is a young man who is only interested in poetry, but he might change when he grows older.

a. John hasn't started showing any interest in business.

b. Presupposition: John hasn't shown interest for business in the past.
} 


\subsection{Breaking the Tie}

The $\mathrm{vFL}$ account might look like the mirror image of the $\mu$ theory but it is not, and here's why. First of all, imagine we extended the vFL account to deal with strong NPIs (which it doesn't). According to Zwarts (1996), strong NPIs must be licensed by an Anti-Additive (AA) function (e.g. 'fewer than three students' is not AA, but 'no student' is):

\section{Anti-Additivity:}

A function $f$ is AA iff $(f(\mathrm{X}) \wedge f(\mathrm{Y})) \Longleftrightarrow f(\mathrm{X} \vee \mathrm{Y})($ Zwarts 1996)

\begin{tabular}{|c|}
\hline Anti-Additive \\
\hline Downward Entailing \\
(i) $f(\mathrm{X}) \vee f(\mathrm{Y}) \Rightarrow f(\mathrm{X} \wedge \mathrm{Y})$ \\
(ii) $f(\mathrm{X} \vee \mathrm{Y}) \Rightarrow f(\mathrm{X}) \wedge f(\mathrm{Y})$ \\
\hline (iii) $f(\mathrm{X}) \wedge f(\mathrm{Y}) \Rightarrow f(\mathrm{X} \vee \mathrm{Y})$ \\
\hline
\end{tabular}

Although only and emotive factives seem to create a suitable environment for weak NPIs, they do not do so for strong ones. This is expected in the $\mu$ theory, as they are not AA. In fact, they are Strawson Anti-Additive (SAA).

Strawson Anti-Additivity:

A function $f$ is Strawson Anti-Additive (SAA)

iff $(f(\mathrm{X}) \wedge f(\mathrm{Y}))$ and $f(\mathrm{X} \vee \mathrm{Y})$ Strawson-entail each other.

Let us show that sorry is not AA (hence disrupts licensing, as desired), but is SAA:

(66) a. John is sorry that Mary is here and is sorry that Peter is here.

b. $\Rightarrow$ John is sorry that Mary or Peter is here.

c. $\operatorname{SORRY}(X) \wedge \operatorname{SORRY}(Y) \Rightarrow \operatorname{SORRY}(X \vee Y)$ (Left to Right)

d. $\operatorname{SORRY}(X) \wedge \operatorname{SORRY}(Y) \Rightarrow{ }^{\text {Strawson }} \operatorname{SORRY}(X \vee Y)($ Left to Right)

(67) a. John is sorry that Mary or Peter is here.

$\mathrm{b} . \not \mathrm{John}$ is sorry that Mary is here and is sorry that Peter is here.

c. $\operatorname{SORRY}(X \vee Y) \nRightarrow \operatorname{SORRY}(X) \wedge \operatorname{SORRY}(Y)($ Right to Left)

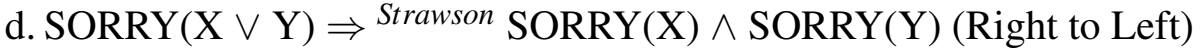

Since sorry doesn't license strong NPIs, the latter don't need an SAA environment but an AA one. Now, what distinguishes Strawson Anti-Additivity from Anti-Additivity tout court is, as the above shows, the right-to-left direction of the equivalence, which is part of downward entailingness: in order to make the right prediction, the $\mathrm{vFL}$ account should thus require, just like the $\mu$ theory, that strong NPIs occur in a strictly DE environment. It would then need to state two separate licensing conditions: strong NPIs require strictly DE environments, while weak NPIs 
require SDE, non SUE ones. ${ }^{10}$ Second, in view of the discrepancy between say too and only, vFL must stipulate that some triggers are disruptors for weak NPIs while others aren't. Once Strawson-entailment is in the picture and the licensing condition of weak NPIs invokes it, what can distinguish too (a disruptor) and only (a non disruptor), which are both SDE, non SUE if not brute force, or some unknown property? Summing up, two stipulations are required in the vFL account: one is the existence of two licensing conditions, the other is the marking of some triggers as non disruptive.

On the other hand, the $\mu$ theory doesn't need a separate licensing condition for strong NPIs: it is a necessary condition for all NPIs, be they weak or strong, that they occur in a DE environment (of course, strong NPIs are subject to some further restrictions, but these must be assumed by both theories). On the other hand, the $\mu$ theory must specify which presuppositions should contribute to the $\mu$ meaning for the licensing of weak NPIs (keeping in mind that no decision has to be made for strong NPIs, given that all presuppositions are included as far as they are concerned). On the whole, the $\mu$ theory is thus more economical than the vFL theory: its superiority lies in the fact that it makes one stipulation instead of two.

Still, one might complain that the stipulation it has to make (some but not all presuppositions count for the $\mu$ meaning as far as weak NPIs are concerned) is unsatisfactorily mysterious. But we think the $\mu$ theory is well designed to elucidate the mystery: in effect, it treats the assertive content and the presupposition(s) of a sentence $\Phi$ as being distinct objects. It is then conceivable that one is manipulated in the absence of the other. If such a circumstance happens, i.e. if only the assertive content of $\Phi$ contributes to the $\mu$ meaning, NPIs will be licensed provided that the assertive content is DE w.r.t. their positions.

As a consequence, we would like to venture the idea, admittedly largely speculative, that the licensing of weak NPIs and the licensing of strong NPIs do not occur at the same stage (assuming the operations performed by the system follow a sequence): suppose there are various classes of presuppositions, which are computed by the system at different stages, and the classes of presuppositions as well as the order of their computation are fixed across languages (our implicational hierarchy is in fact a sketch of this architecture: the higher a trigger is on a scale, the later its presupposition enters the system). And suppose that what varies, across categories of NPIs ${ }^{11}$ and across languages, is the stage at which licensing is checked, or in other words, the stage at which the $\mu$ meaning gets computed: this would derive the differing disruptive potentials of triggers, the weak/strong dissimilarity, and the cross-linguistic variations. For example, checking the licensing of any in English might happen before the presuppositions of cognitive factives are computed, while the licensing of quoi que ce soit in French would be checked later; the presupposi-

\footnotetext{
${ }^{10}$ Gajewski (2008) independently arrives at the same conclusion, but departs from our proposal in significant respects, e.g. it resorts to Strawson-entailment and relies on an operator-based licensing principle.

${ }^{11}$ It is natural to imagine that within a given language, the stage of licensing varies across NPIs of the same category (i.e. weak or strong), although the data collected so far don't corroborate this hypothesis.
} 
tion of too and aussi would of course be computed earlier than the licensing stage. ${ }^{12}$ Strong NPIs, which are characterized by their idiomatic nature (this is at least clear for minimizers) could possibly belong to some very high level, and their licensing be checked at a late stage, when all presuppositions have been computed (at any rate the ones we've looked at). ${ }^{13}$ We predict that some language should exist in which one of the high triggers on the scale, e.g. stop, is a disruptor for weak NPIs (and all triggers below it are too).

\section{Conclusion}

This paper shows that presuppositions can affect NPI licensing: in doing so, it lends decisive support to the view that inferences can disrupt licensing, and it deprives the idea of Strawson-entailment of its empirical justification.

\section{References}

Chierchia, Gennaro: 2004, 'Scalar Implicatures, Polarity Phenomena, and the Syntax/Pragmatics Interface', in A. Belletti (ed.), Structures and Beyond, 39103. Oxford.

von Fintel, Kai: 1999, 'NPI-Licensing, Strawson-Entailment, and ContextDependency', Journal of Semantics 16, 97-148.

Gajewski, Jon: 2005, Neg-Raising: Polarity and Presupposition, Doctoral Dissertation, MIT, Cambridge, Mass.

Gajewski, Jon: 2008, 'Licensing Strong NPIs'. Manuscript.

Giannakidou, Anastasia: 2006, 'Only, Emotive Factive Verbs, and the Dual Nature of Polarity Dependency', Language $\mathbf{8 2}$.

Guerzoni, Elena and Yael Sharvit: 2007, 'A Question of Strength: on NPIs in Interrogative Clauses', Linguistics and Philosophy $\mathbf{3 0 .}$

Homer, Vincent: 2007, 'Intervention Effects: the Case of Presuppositions'. Master's thesis, UCLA, Los Angeles.

Homer, Vincent: 2008, 'Presuppositions Can Be Disruptors Too: a Case against Strawson-Entailment', in Proceedings of WCCFL XXVII. Cascadilla Press.

Lahiri, Utpal: 1998, 'Focus and Negative Polarity in Hindi', Natural Language Semantics 6, 57-123.

Zwarts, F.: 1996, 'Three Types of Polarity', in F. Hamm and E. Hinrichs (eds.), Plural Quantification. Kluwer, Dordrecht.

\footnotetext{
${ }^{12}$ Alternatively, and maybe more orthodoxly, one could say that the module in which licensing is checked doesn't necessarily have access to all modules where presuppositions are computed.

${ }^{13}$ Bearing in mind that scalar implicatures are consistent disruptors, our little conjecture might have far-reaching consequences on the widespread view that implicatures are somehow more peripheral than presuppositions.
} 